\title{
Perpaduan Determinan Individu dan Tingkat Ekologi terhadap Kejadian Infeksi Malaria di Endemis Malaria
}

\author{
The Integration of Individual Determinants and Ecological Levels in Incidence \\ of Malaria Infection in Malaria Endemic
}

\author{
Artha Budi Susila Duarsa* \\ Fakultas Kedokteran Universitas Islam Al-azhar \\ (*duarsaartha@gmail.com)
}

\begin{abstract}
ABSTRAK
Penelitian epidemiologi malaria berkaitan dengan faktor risiko terbatas untuk mengetahui biobehavioral effect pada tingkat individu. Analisis determinan pada berbagai tingkat dengan problem metodologisnya belum banyak dipertimbangkan oleh para ahli epidemiologi sampai saat ini. Penelitian ini menggunakan Studi Ekologi desain hybrid. Studi kualitatif dilakukan untuk melihat parameter kondisi desa dalam merespon kebijakan operasional program pencegahan malaria. Analisis yang dilakukan adalah multilevel logistic regression dan content analysis. Sampel diambil secara bertingkat dari 1.206 penduduk pada 240 rumah tangga di 30 desa pada 3 kecamatan endemis malaria, Kabupaten Lampung Selatan dan Pesawaran. Ditemukan kejadian infeksi malaria [dengan indikator parasit (+)] di 30 desa kecamatan endemis malaria Kabupaten Lampung Selatan dan Pesawaran adalah $11,2 \%$, dengan gambaran jenis plasmodium malaria sebagian besar adalah $55,8 \%$ P. Vivax, dikuti dengan P. Falciparum (41,5\%), dan yang terendah adalah P. Malariae (2,7\%). Besar peran tingkat individu (level 1) $0,17 \%$, besar peran tingkat rumah tangga (level 2) 43,8\% dan besar peran tingkat desa (level 3) 55,9\% dalam menjelaskan kejadian infeksi malaria. Kesimpulan dari hasil penelitian didapatkan perbedaan kejadian infeksi malaria pada individu lebih ditentukan oleh faktor kontekstual (tingkat rumah tangga (level 2) dan tingkat desa (level 3) dibandingkan faktor komposisional (tingkat individu (level 1).
\end{abstract}

Kata kunci : Infeksi malaria, multilevel, kontekstual, komposional

\begin{abstract}
Epidemiological studies of malaria regarding risk factors are limited to knowing the biobehavioral effect at the individual level. Determinant analysis at various levels with various methodological problems has not been widely considered by epidemiologists to date. This study used hybrid design ecological studies. Qualitative studies were conducted to look at the parameters of village conditions in response to operational policies on malaria prevention programs. The analysis carried out was multilevel logistic regression and content analysis. Samples were taken in stages from 1,206 residents in 240 households in 30 villages in 3 malaria endemic districts of South Lampung Regency \& Pesawaran. The incidence of malaria infection was found [with parasitic indicators $(+)$ ] in 30 malaria endemic sub-villages in South Lampung Regency \& Pesawaran District of $11.2 \%$, with the majority of malaria plasmodium species being $55.8 \%$ P. Vivax, followed by P. Falciparum (41.5\%), and the lowest was P. Malariae (2.7\%). The role of the individual level (level 1) is $0.17 \%$, the role of the household level (level 2) is $43.8 \%$ and the role of the village level (level 3 ) is $55.9 \%$ in explaining the incidence of malaria infection. Conclusions from the results of the study found that the difference in incidence of malaria infection in individuals is more determined by contextual factors (level of household (level 2) and village level (level 3) compared to compositional factors (individual level (level 1).
\end{abstract}

Keywords : Malaria infection, multilevel, contextual, compost

Copyright (C) 2019 by author. This is an open access article under the CC BY-NC-SA license

(https://creativecommons.org/licenses/by-nc-sa/4.0/).

DOI : http://dx.doi.org/10.30597/mkmi.v15i3.6731 


\section{PENDAHULUAN}

Malaria dikenal sebagai penyakit parasit tropis dan salah satu dari pembunuh tiga besar penyakit menular dan sampai saat ini malaria masih menjadi masalah kesehatan terbesar di dunia. Terdapat 300 sampai 500 juta kasus setiap tahun dan diantaranya satu sampai tiga juta meninggal, kebanyakan adalah anak-anak. ${ }^{1}$

Malariajuga masih merupakan masalahkesehatan yang besar di Indonesia. Hampir semua daerah di luar Jawa dan Bali merupakan daerah endemis. Sebagian penduduk di 20 Propinsi di Indonesia terjangkit malaria. Lebih dari 40 juta penduduk tinggal di daerah malaria dan sekitar 11 juta diantaranya tinggal di Jawa dan Bali. ${ }^{2}$ Jawa dan Bali yang diprioritaskan dalam program pemberantasan malaria, tingkat penularan malaria pernah diturunkan secara berarti. Saat ini tidak kurang dari 20 kecamatan di Jawa-Bali, 14 diantaranya di Jawa Tengah, kembali menunjukkan tingkat penularan malaria yang cukup tinggi (resurgent/ reemerging).

Pulau luar Jawa dan Bali, hampir semua daerahnya memiliki tingkat penularan malaria yang tinggi. Kejadian Luar Biasa (KLB) malaria terjadi di pulau Bintan, Aceh (daerah transmigrasi) dan Kabupaten Jaya Wijaya Irian Jaya pada tahun 1997. ${ }^{3}$ Kejadian KLB juga terjadi di Kabupaten Indra Giri Hilir Propinsi Riau Tahun 2004 yang menyebabkan 27 orang meninggal. ${ }^{4}$ Tahun 2015 terjadi lagi KLB di 12 Kabupaten/Kota di 12 Propinsi yang menyebabkan 118 kematian. KLB di Kabupaten Lombok Timur Propinsi Nusa Tenggara Barat yang terjadi pada bulan Oktober merupakan KLB malaria yang terjadi diakhir tahun 2015, yang menyebabkan 13 orang meninggal. ${ }^{5}$

Penelitian epidemiologi mengenai malaria yang telah banyak dilakukan selama ini adalah penelitian mengenai faktor risiko terjadinya malaria yang pengukurannya bertujuan untuk mengetahui biobehavioral effect pada tingkat individu. Indonesia belum banyak dilakukan penelitian mengenai faktor risiko terjadinya malaria yang menggabungkan analisis pada tingkat individu dan tingkat ekologi (agregat, lingkungan dan global).

Faktor risiko di berbagai tingkat pengukuran disebut sebagai determinan kontekstual (ekologi/ agregat) yang ikut berperan terhadap terjadinya malaria. Peran determinan kontekstual (ekolo- gi/agregat) terhadap terjadinya malaria bersama dengan faktor risiko di tingkat individu merupakan suatu permasalahan yang menarik dan sangat penting untuk diketahui dan diteliti. Sesungguhnya peran determinan ekologi/agregat terhadap terjadinya malaria, seberapa besar peran determinan ekologi/agregat tersebut dan peran determinan ekologi/agregat tersebut secara bersama-sama dengan faktor risiko di tingkat individu. Adapun tujuan penelitian ini adalah untuk menjelaskan variasi kejadian infeksi malaria, indikator parasit, dan gambaran jenis plasmodium infektif.

\section{BAHAN DAN METODE}

Penelitian ini merupakan penelitian kuantitatif eksploratif, menggunakan studi ekologi desain hybrid dimana dua langkah skema sampling digunakan yaitu untuk memilih kelompok (langkah 1), yang diikuti oleh pemilihan individu di dalam kelompok (langkah 2). ${ }^{6}$ Populasi penelitian ini adalah seluruh masyarakat yang tinggal di 30 desa di tiga kecamatan endemis malaria Kabupaten Lampung Selatan dan Pesawaran yaitu Kecamatan Rajabasa, Kecamatan Padang Cermin dan Kecamatan Punduh Pidada. Sebanyak 1.206 orang pada 240 rumah tangga sebagai sampel pada penelitian ini dengan teknik pengambilan sampel Multistage Cluster.

Teknik pengumpulan data dilakukan menggunakan instrumen berupa kuesioner yang sudah dilakukan penilaian validitas dan reliabilitas sebelum penelitian dan pedoman wawancara yang dilakukan dengan wawancara mendalam (in-depth interview) dan diskusi kelompok terarah (Focus Group Discussion). Data yang dikumpulkan selanjutnya dianalisis dengan regresi logistik multilevel yang menggunakan program statistik Stata 8 untuk mengetahui faktor-faktor yang mempengaruhi kejadian infeksi malaria. Sementara analisis data kualitatif menggunakan analisis isi (content analysis) dengan menggunakan hasil wawancara mendalam dan diskusi kelompok terarah yang telah direduksi ke dalam matriks. Penelitian ini dilakukan uji validitas (triangulasi) yaitu triangulasi sumber, triangulasi metode dan triangulasi data.

\section{HASIL}

Tabel 1 menunjukkan bahwa proporsi kejadian infeksi malaria yang ditandai dengan parasit 
Tabel 1. Distribusi Kejadian Infeksi Malaria Kecamatan Endemis Malaria Kabupaten Lampung Selatan dan Pesawaran Tahun 2016 ( $n=1.206$ responden)

\begin{tabular}{lcc}
\hline \multicolumn{1}{c}{ Variabel } & $\mathbf{\%}$ & CI 95\% \\
\hline Infeksi Malaria [Parasit (+)] & 11,2 & $6,70-18,8$ \\
Tidak infeksi Malaria [Parasit (-)] & 88,8 & $8,20-93,3$ \\
\hline
\end{tabular}

Sumber : Data Primer, 2016

Tabel 2. Distribusi Jenis Plasmodium Malaria Kecamatan Endemis Malaria Kabupaten Lampung Selatan dan Pesawaran Tahun 2016 (n=1.206 responden)

\begin{tabular}{lcc}
\hline \multicolumn{1}{c}{ Variabel } & $\mathbf{\%}$ & CI 95\% \\
\hline Jenis Plasmodium & & \\
Falciparum & 41,5 & $26,9-57,8$ \\
Vivax & 55,8 & $39,0-71,3$ \\
Malariae & 2,7 & $1,10-6,80$ \\
\hline
\end{tabular}

Sumber : Data Primer, 2016

(+) di tiga kecamatan endemis malaria Kabupaten Lampung Selatan dan Pesawaran adalah sebesar $11,2 \%$, CI 95\% (6,70\%-18,8\%) atau yang terinfeksi malaria kurang lebih $1 / 8$ dari seluruh responden. Tabel 2 menunjukkan bahwa proporsi Plasmodium tertinggi adalah P.Vivax sebesar 55,8\%, CI 95\% (39,0\%-71,3\%), diikuti dengan P. Falciparum sebesar $41,5 \%$, CI 95\% (26,9\%-57,8\%) dan yang terendah adalah $P$. Malariae sebesar 2,7\%, CI 95\% (1,10\%-6,80\%). Hasil analisis Regresi Logistik Multilevel untuk Kejadian Infeksi Malaria tahun 2016 pada Tabel 3, menunjukkan bahwa variabel-variabel di tingkat individu, yang terdiri dari pekerjaan, kemoprofilaksis dan usia tidak memiliki pengaruh yang kuat terhadap kejadian infeksi malaria. Berdasarkan Tabel 4 diketahui bahwa OR variabel pekerjaan setelah variabel-variabel tingkat individu (level 1), variabel-variabel tingkat rumah tangga (level 2) dan variabel-variabel tingkat desa (level 3) dimasukkan ke dalam model adalah 1,82. Artinya, individu yang memiliki pekerjaan berisiko memiliki peluang untuk terinfeksi malaria sebesar 1,82 kali dibandingkan dengan individu yang memiliki pekerjaan tidak berisiko.

Nilai varians pada tingkat individu (level 1), diperoleh secara manual, karena nilai varians pada tingkat individu (level 1) tidak terdapat pada hasil keluaran analisis Regresi Logistik Multilevel. Besar nilai varians pada tingkat individu (level 1) adalah 0,00418. Nilai ICC menggambarkan besar peran tingkat individu (level 1), tingkat rumah tangga (level 2) dan tingkat desa (level 3) terhadap kejadian infeksi malaria. Hasil perhitungan ICC tersebut diketahui, besar peran tingkat individu (level 1) $0,17 \%$, besar peran tingkat rumah tangga (level 2) $43,8 \%$ dan besar peran tingkat desa (level 3) $55,9 \%$.

Tabel 3, diketahui perbandingan model (1) dan (2) terjadi peningkatan nilai varians pada level 2 dari 1,0509 menjadi 1,1135 dan terjadi peningkatan nilai varians pada level 3 dari 1,3425 menjadi 1,4796. Ini menunjukkan variabel-variabel ditingkat individu tidak memiliki pengaruh yang kuat dalam menekan variasi yang terjadi pada kejadian infeksi malaria. Hal ini menunjukkan bahwa variabel-variabel di tingkat individu, yang terdiri dari pekerjaan, kemoprofilaksis dan usia tidak memiliki pengaruh yang kuat terhadap kejadian infeksi malaria.

Perbandingan model (2) dan (3) terjadi peningkatan nilai varians pada level 2 dari 1,1135 menjadi 1,1336 dan terjadi penurunan nilai varians pada level 3 dari 1,4796 menjadi 1,4594. Hal ini berarti variabel-variabel ditingkat rumah tangga, yang terdiri dari jarak rumah sedang, jarak rumah dekat dan lingkungan tempat perindukan nyamuk memiliki pengaruh yang kuat dalam menekan variasi yang terjadi pada kejadian infeksi malaria pada tingkat rumah tangga (Tabel 3). Besar peran variabel-variabel ditingkat di rumah tangga dihitung menggunakan PCV (Proportional Change in Variation $){ }^{7}$ Besar peran variabel-variabel ditingkat rumah tangga, yang terdiri dari jarak rumah sedang dengan tempat perindukan nyamuk, jarak rumah dekat dengan tempat perindukan nyamuk dan 
Tabel 3. Analisis Regresi Logistik Multilevel Untuk Kejadian Infeksi Malaria Tahun 2016 (1.206 responden, 240 rumah tangga, 30 Desa, 3 kecamatan)

\begin{tabular}{|c|c|c|c|c|}
\hline & $\begin{array}{c}\text { Model 1 } \\
\text { (null model) }\end{array}$ & $\begin{array}{c}\text { Model 2 } \\
\text { (Individu) }\end{array}$ & $\begin{array}{c}\text { Model 3 } \\
\text { (Rumah Tangga) }\end{array}$ & $\begin{array}{c}\text { Model } 4 \\
\text { (Desa) }\end{array}$ \\
\hline \multicolumn{5}{|l|}{ Fixed Effect, dalam kelompok } \\
\hline \multicolumn{5}{|l|}{ Koefesien Regresi (SE) } \\
\hline \multicolumn{5}{|l|}{ Determinan Tk. Individu } \\
\hline Pekerjaan & & $0,596(0,291)$ & $0,599(0,291)$ & $0,596(0,292)$ \\
\hline Kemoprofilaksis & & $0,790(0,253)$ & $0,806(0,255)$ & $0,748(0,255)$ \\
\hline Usia & & $0,027(0,008)$ & $0,027(0,008)$ & $0,027(0,008)$ \\
\hline \multicolumn{5}{|l|}{ Determinan Tk. Rumah Tangga } \\
\hline Jarak rumah sedang & & & $0,290(0,414)$ & $0,199(0,414)$ \\
\hline Jarak rumah dekat & & & $0,576(0,348)$ & $0,181(0,349)$ \\
\hline Lingkungan perindukan nyamuk & & & $0,182(0,329)$ & $0,194(0,331)$ \\
\hline \multicolumn{5}{|l|}{ Determinan Tk. Desa } \\
\hline Kepadatan penduduk & & & & $0,359(0,676)$ \\
\hline Pertumbuhan penduduk & & & & $1,207(0,554)$ \\
\hline Penyuluhan & & & & $1,453(0,713)$ \\
\hline SKD-KLB & & & & $0,795(0,533)$ \\
\hline \multicolumn{5}{|l|}{ Random Effec (SE) } \\
\hline Varians level 2 (tingkat rumah tangga) & 1,0509 & 1,1135 & 1,1336 & 1,1602 \\
\hline Varians level 3 (tingkat desa) & 1,3425 & 1,4796 & 1,4594 & 0,8059 \\
\hline
\end{tabular}

Sumber : Data Primer, 2016

lingkungan tempat perindukan nyamuk terhadap kejadian infeksi malaria sebesar $1,37 \%$. Artinya, variabel-variabel di tingkat rumah tangga tersebut dapat menerangkan $1,37 \%$ variasi yang terjadi pada tingkat rumah tangga. Hal ini tidak sejalan dengan ICC pada tingkat rumah tangga (level 2) yang memiliki peranan yang cukup besar terhadap kejadian infeksi malaria yaitu $43,8 \%$.

Perbandinganmodel(3)dan(4)terjadipeningkatan nilai varians level 2 dari 1,1336 menjadi 1,1602 dan terjadi penurunan yang cukup besar nilai varians level 3 dari 1,4594 menjadi 0,8059 . Hal ini berarti bahwa, variabel-variabel ditingkat desa yang terdiri dari kepadatan penduduk, pertumbuhan penduduk, penyuluhan kesehatan tentang malaria dan SKD-KLB malaria memiliki pengaruh yang kuat dalam menekan variasi yang terjadi pada kejadian infeksi malaria pada tingkat desa. Hal ini menunjukkan bahwa variabel ditingkat desa tersebut mempunyai pengaruh yang cukup kuat terhadap kejadian infeksi malaria (Tabel $3)$.

Besar peran/PCV (Proportional Change in Variation) variabel-variabel ditingkat desa, yang terdiri dari kepadatan penduduk, pertumbuhan penduduk, penyuluhan kesehatan tentang malaria dan SKD-KLB malaria terhadap kejadian infeksi malaria sebesar $44,78 \%$. Artinya, variabel-variabel di tingkat desa tersebut dapat menerangkan $44,78 \%$ variasi yang terjadi pada tingkat desa. Hal ini sejalan dengan ICC pada tingkat desa (level 3) yang memiliki peranan yang besar terhadap kejadian infeksi malaria yaitu 55,9\%. Besar peran/PCV (Proportional Change in Variation) variabel-variabel di level 1 (tingkat individu), level 2 (tingkat rumah tangga) dan level 3 (tingkat desa) adalah $39,97 \%$. Artinya, variabel-variabel ditingkat individu, variabel-variabel ditingkat rumah tangga dan variabel-variabel ditingkat desa dapat menerangkan $39,97 \%$ variasi yang terjadi pada semua tingkat.

\section{PEMBAHASAN}

Angka kejadian infeksi malaria di tiga kecamatan daerah endemis malaria berdasarkan plasmodium malaria $(+)$ adalah sebesar $11,2 \%$. Hasil penelitian ini lebih besar dari angka kejadian infeksi malaria di Kabupaten Lampung Selatan \& Pesawaran, yang berdasarkan API pada tahun 2015 sebesar 2,6\% dan tahun 2016 sebesar 1,7\%. Hasil penelitian ini juga lebih besar dari angka kejadian infeksi malaria di tiga kecamatan ende- 
Tabel 4. Odds Ratio Untuk Peluang Responden Terinfeksi Malaria Kecamatan Endemis Malaria Kabupaten Lampung Selatan dan Pesawaran Tahun 2016

\begin{tabular}{lccc}
\hline & Level 1 & Level 1 dan 2 & Level 1, 2 dan 3 \\
\hline $\begin{array}{l}\text { Fixed Effect, dalam kelompok } \\
\text { Odds Ratio (OR) }\end{array}$ & & \\
Determinan Tk. Individu & & & \\
$\quad$ Pekerjaan & 1,82 & 1,82 & 1,82 \\
$\quad$ Kemoprofilaksis & 2,20 & 2,23 & 2,11 \\
$\quad$ Usia & 1,03 & 1,03 & 1,03 \\
Median Odds Ratio (MOR) & & & \\
$\quad$ Rumah Tangga & 2,74 & 3,01 & 2,19 \\
$\quad$ Desa & 3,19 & 3,17 & \\
Interval Odds Ratio (IOR) & & & 1,16 \\
Determinan Tingkat Rumah Tangga & & 1,00 & $(5,64-8,40)$ \\
$\quad$ Jarak rumah jauh & & $(5,15-9,20)$ & $(5,74-8,25)$ \\
$\quad$ Jarak rumah sedang & & $(3,87-12,24)$ & 1,00 \\
$\quad$ Jarak rumah dekat & & $(5,74-8,26)$ & $(5,67-8,36)$ \\
$\quad$ Tidak ada lingkungan perindukan nyamuk & & & 1,00 \\
$\quad$ Ada lingkungan perindukan nyamuk & & & $(4,92-10,09)$ \\
Determinan Tk. Desa & & & 1,00 \\
$\quad$ Kepadatan penduduk rendah & & & $(2,52-19,67)$ \\
$\quad$ Kepadatan penduduk tinggi & & $(4,58-20,12)$ \\
$\quad$ Pertumbuhan penduduk rendah & & 1,00 \\
$\quad$ Pertumbuhan penduduk tinggi & & $(3,18-15,60)$ \\
$\quad$ Penyuluhan kesehatan baik & &
\end{tabular}

mis malaria Kabupaten Lampung Selatan dan Pesawaran berdasarkan API pada tahun 2015 sebesar $31,4 \%$ dan tahun 2016 sebesar 19,9\%.

Perbedaan angka kejadian infeksi malaria tersebut disebabkan beberapa hal, yaitu: (1) Laporan penemuan penderita malaria Kabupaten Lampung Selatan \& Pesawaran merupakan laporan kumulatif dari 32 Puskemas di 20 kecamatan yang terdiri dari daerah endemis malaria dan tidak endemis malaria, sehingga angka kejadian infeksi malaria dari laporan penemuan penderita malaria menggambarkan angka penderita malaria yang datang berobat ke Puskesmas seluruh kecamatan yang ada di Kabupaten Lampung Selatan \& Pesawaran berdasarkan laporan bulanan Puskesmas; (2) laporan penemuan penderita malaria tiga kecamatan daerah endemis malaria, Kabupaten Lampung Selatan dan Pesawaran merupakan laporan kumulatif dari 4 Puskemas (12,5\% dari total Puskesmas) di tiga kecamatan (15\% dari total kecamatan) daerah endemis malaria, sehingga angka kejadian infeksi malaria dari laporan penemuan penderita malaria tersebut menggambarkan angka penderita malaria yang datang berobat ke puskesmas di tiga kecamatan endemis malaria Kabupaten Lampung Selatan \& Pesawaran berdasarkan laporan bulanan Puskesmas, (3) laporan penemuan penderita malaria, pemeriksaan sediaan darah dilakukan pada penderita malaria klinis yang datang berobat ke puskesmas, cara ini disebut dengan Passive Case Detection (PCD). Penelitian ini, subyek yang terpilih, baik dengan gejala klinis malaria atau tidak memiliki gejala klinis malaria dilakukan pemeriksaan sediaan darah malaria dengan melakukan kunjungan ke rumah Active Case Detection (ACD), sehingga angka kejadian infeksi malaria hasil penelitian ini menggambarkan angka kejadian infeksi malaria yang terjadi di populasi tiga kecamatan endemis malaria.

Hasil penelitian ini menunjukkan bahwa Parasite Formula (PF) adalah P. Vivax dominan. Hasil survei Balitbangkes Depkes RI tahun 2002 
menujukkan bahwa PF P. Falciparum dominan, PF Kabupaten Lampung Selatan dan Pesawaran tahun 2015 dan 2016 menunjukkan P. Falciparum domi-nan, PF Kecamatan Padang Cermin tahun 2015 dan 2016 menunjukkan $P$. Falciparum dominan, PF Puskesmas Hanura tahun 2015 dan 2016 adalah P. Falciparum dominan, PF Puskesmas Padang Cermin tahun 2015 adalah P. Falciparum dominan tapi pada tahun 2016 P. Vivax dominan. PF Puskesmas Pidada Kecamatan Punduh Pidada tahun 2015 dan 2016 menunjukkan $P$. Vivax dominan, sedangkan PF Puskesmas Way Muli Kecamatan Rajabasa tahun 2015 dan 2016 menunjukkan $P$. Falciparum dominan. ${ }^{8}$ Perbedaan hasil tersebut kemungkinan besar disebabkan: (1) Waktu pelaksanaan pengumpulan data yang berbeda, dimana survey Balitbangkes Depkes RI dilaksanakan pada periode Mei-Juni 2002, laporan penemuan penderita malaria Dinas Kesehatan Kabupaten Lampung Selatan \& Pesawaran tahun 2015 dan 2016 berasal dari laporan kumulatif Puskesmas dalam satu tahun pada tahun tersebut, sedangkan penelitian ini dilaksanakan pada perio-de Agustus-September 2016; (2) pemberian peng-obatan terhadap penderita malaria di Puskemas Padang Cermin dan Puskesmas Punduh Pidada masih banyak dilakukan pengobatan malaria klinis dengan klorokuin; ${ }^{8}$ (3) pemberian klorokuin pada penderita malaria dengan P. Falciparum $(+)$, padahal sesuai dengan standar pengobatan di daerah endemis malaria penderita malaria dengan $P$. Falciparum $(+)$ harus diberikan ACT (Artemisinin Combination Therapy), ${ }^{9}(4)$ adanya resistensi terhadap klorokuin di tiga kecamatan daerah endemis malaria. $^{10}$

Keberhasilan pemberantasan malaria di Indonesia pernah terjadi pada periode tahun 19191927, melalui perbaikan sanitasi lingkungan yang spesifik untuk mengurangi nyamuk anopheles. Keperluan tersebut dibentuk Biro Malaria Pusat yang bersama Dinas Pekerjaan Umum mengadakan pemberantasan malaria dengan membuat pengaturan irigasi, pengaturan saluran air (drainase), penimbunan dan penyaluran genangan air dan lagun. ${ }^{11}$

Sahli tahun 2003 dalam Kholis Ernawati, Budhi Soesilo, dkk memberikan gambaran bahwa kejadian infeksi malaria di Propinsi Lampung sebagian besar disebabkan oleh variabel-variabel yang berada di tingkat rumah tangga (level 2) dan tingkat desa (level 3). Penjelasan Sahli tersebut semakin menegaskan bahwa dalam kejadian infeksi malaria di Propinsi Lampung, peranan tingkat individu (level 1) (Compositional Factor) adalah sangat kecil dibandingkan peranan faktor kontekstual (Contextual Factor) atau faktor ekologi/ lingkungan (Ecological/Environmental), yaitu peran tingkat rumah tangga (level 2), peran tingkat desa (level 3) dan tingkat yang lebih atas lagi. ${ }^{12}$

Merujuk pada kerangka teori yang dibangun dengan paradigma model terintegrasi terjadinya malaria (Integrated Assesment Model) dari Fischoff, dkk dalam Helen Elsy sebagai dasar utama pembuatan kerangka teori maka hubungan variabel-variabel pekerjaan, kemoprofilaksis dan usia dengan variabel-variabel lainnya terhadap kejadian infeksi malaria adalah sebagai berikut: usia, pekerjaan dan pemakaian kemoprofilaksis dipengaruhi oleh potensi desa, sumber daya masyarakat, kegiatan pencegahan malaria yang dilakukan masyarakat, pertumbuhan penduduk dan kepadatan penduduk yang berada dalam parameter kondisi sosial, ekonomi dan politik daerah. ${ }^{13}$

Potensi terjadinya kejadian infeksi malaria akan tergantung kepada kapasitas puskesmas dalam pencegahan primer malaria untuk mencegah terjadinya malaria dan membatasi dampaknya terhadap kesehatan masyarakat dengan melaksanakan kegiatan SKD-KLB malaria yang terfokus kepada lingkungan tempat perindukan nyamuk dalam parameter habitat, vektor (nyamuk anopheles) dan parasit (plasmodium).

Penelitian ini menunjukkan peranan variabel-variabel di tingkat individu (level 1) sangat kecil dalam menjelaskan variasi kejadian infeksi malaria yang terjadi, tetapi berdasarkan hasil analisis bivariat penelitian ini dan berbagai penelitian terdahulu menunjukkan bahwa intervensi potensial untuk mencegah kejadian infeksi malaria pada penduduk di daerah endemis malaria adalah dengan melaksanakan kegiatan pencegahan malaria yang berkaitan dengan pengetahuan dan perilaku individu dalam menghindari/mengurangi gigitan (kontak) nyamuk anopheles. Berdasarkan hal itu, maka pelaksanaan kegiatan pencegahan malaria di tingkat individu (level 1) seperti pemakaian kelambu, pemakaian obat nyamuk, pemakaian reppelent, menggunakan penutup tubuh pada ak- 
tivitas di luar rumah pada malam hari dan mengurangi aktivitas di luar rumah pada malam hari serta penggunaan obat ACT (Artemisinin Combination Therapy) tetap merupakan kegiatan yang penting dalam pengendalian malaria di daerah endemis. Intervensi pengendalian malaria pada tingkat individu (level 1) tersebut merupakan intervensi antara (intermediate) yang penting selama faktor kontekstual (agregat/ekologi) di tingkat rumah tangga (level 2) dan tingkat desa (level 3) belum dapat dikendalikan secara optimal.

Penelitian ini sesuai dengan hasil penelitian kualitatif terdahulu yang mendapatkan hasil bahwa, tempat tinggal dan tempat bekerja yang lebih dekat dengan tempat perkembangbiakan vektor mempunyai risiko lebih tinggi terhadap penularan malaria. Sebagaimana penjelasan Sudomo dalam Hasan, dimana di tiga kecamatan endemis malaria tersebut banyak ditemukan genangan tempat perindukan nyamuk Anopheles yang berupa genangan air payau dan genangan air tawar. ${ }^{14}$ Adanya krisis ekonomi pada tahun 1997 mengakibatkan $60 \%$ tambak udang terlantar, yang berkaitan dengan bertambahnya tempat perindukan nyamuk An. Sundaicus. Penelitian Sumantri, juga menjelaskan bahwa munculnya tambak udang yang terbengkalai akan menimbulkan tempat perindukan baru. ${ }^{15}$ Gambaran tempat perindukan nyamuk di tiga kecamatan daerah endemis malaria ditampilkan dalam lampiran tabel 4 .

Hasil penelitian kualitatif tersebut juga sesuai dengan penjelasan Sahli dalam Kholis Ernawati, Budhi Soesilo, dkk bahwa kejadian infeksi malaria di Propinsi Lampung disebabkan oleh tambak yang tidak terawat dan penebangan hutan bakau yang menyebabkan kepadatan vektor tinggi, yang dalam penelitian ini dimasukkan dalam variabel tingkat rumah tangga (level 2). ${ }^{12}$ Merujuk pada kerangka teori yang dibangun dengan paradigma model terintegrasi terjadinya malaria (Integrated Assesment Model) dari Fischoff dkk, dalam Helen Elsey sebagai dasar utama pembuatan kerangka teori, maka hubungan variabel-variabel kegiatan pencegahan malaria oleh masyarakat, sumber daya masyarakat, lingkungan tempat perindukan nyamuk dan jarak rumah dengan tempat perindukan nyamuk berkaitan dengan variabel-variabel lainnya terhadap kejadian infeksi malaria dapat dijelaskan sebagai berikut: kegiatan pencegahan malaria oleh masyarakat dan sumber daya masyarakat yang berada dalam parameter kondisi sosial, ekonomi dan politik daerah akan mempengaruhi pelaksanaan kegiatan SKD-KLB malaria dan penyuluhan kesehatan tentang malaria yang berada dalam parameter kapasitas puskesmas dalam pencegahan primer malaria. ${ }^{13}$

Lingkungan tempat perindukan nyamuk dan jarak rumah dengan tempat perindukan nyamuk yang bervariasi secara langsung akan mempengaruhi parameter vektor (nyamuk anopheles) dan parasit (plasmodium). Potensi terjadinya kejadian infeksi malaria akan tergantung pada kapasitas puskesmas dalam pelaksanan kegiatan SKD-KLB malaria dan penyuluhan kesehatan tentang malaria untuk mencegah terjadinya infeksi malaria dengan melaksanakan intervensi terhadap lingkungan dengan melakukan manajemen lingkungan dengan melakukan modifikasi lingkungan tempat perindukan nyamuk, intervensi terhadap vektor dengan penyemprotan insektisida, larvasida dan intervensi terhadap individu dengan pencarian serta pengobatan penderita secara aktif dan membatasi dampaknya terhadap kesehatan masyarakat.

Kegiatan pencegahan malaria yang dilakukan masyarakat dan ketersedian sumberdaya yang cukup baik yang terdapat di desa-desa daerah penelitian tersebut sesuai dengan Health Belief Model (HBM) yang merupakan expectancy theory, dimana konsep ini dirumuskan untuk melihat hubungan perilaku dengan kesehatan melalui dua jalan yaitu: a) Keinginan untuk menghindarkan diri dari penyakit atau memperoleh sesuatu keadaan yang lebih baik, b) kepercayaan bahwa adanya kegiatan atau aktivitas kesehatan yang spesifik dapat mencegah terjadinya penyakit. ${ }^{16}$

Berdasarkan kriteria Departemen Kesehatan dan UNICEF tahun 1999, masyarakat di ketiga daerah penelitian tersebut telah memenuhi syarat untuk meningkatkan kegiatan pemberdayaan masyarakat dalam rangka pencegahaan dan pemberantasan malaria, karena telah memiliki: (1) Соттиnity Knowledge: masyarakat di ketiga daerah penelitian tersebut telah memiliki pengetahuan tentang malaria; (2) Community Technology: masyarakat di ketiga daerah penelitian tersebut memiliki keterampilan dan teknologi tepat guna yang berkaitan dengan kemampuan masyarakat dalam memelihara dan meningkatkan kesehatannya; (3) 
Community Decision Making: masyarakat di ketiga daerah penelitian tersebut telah melakukan pengambilan keputusan melalui penemuan masalah, perencanaan dan kegiatan pemecahan masalah tersebut; (4) Community Leaders: ketiga daerah penelitian tersebut terdapat pemimpin masyarakat baik formal maupun informal, seperti adanya tokoh masyarakat dan tokoh agama; (5) Сотmunity Organization: ketiga daerah penelitian tersebut terdapat organisasi kemasyarakatan, kelembagaan atau kelompok-kelompok kegiatan masyarakat, (6) Community Fund: ketiga daerah penelitian tersebut terdapat sumber dana yang bisa digali untuk kegiatan kesehatan. ${ }^{17}$

Besar peran dan kekuatan hubungan variabel di tingkat desa (Level 3) dalam penelitian ini sesuai dengan penelitian yang dilakukan Hung, Q Le, Vries, de Peter J., Giao, et al yang menjelaskan bahwa pelaksanaan program pendidikan kesehatan menyebabkan peningkatan partisipasi masyarakat dalam penggunaan kelambu yang telah dipoles insektisida, diagnosa dini mikroskopis dan pengobatan parasitemia, sehingga menjadikan pengendalian malaria di Vietnam berhasil dengan baik. ${ }^{18}$ Menurut Sahli dalam Kholis Ernawati, Budhi Soesilo, dkk bahwa kejadian infeksi malaria di Propinsi Lampung disebabkan oleh variabel-variabel yang berada di tingkat desa (level 3), yaitu promosi kesehatan yang tidak berjalan efektif yang menyebabkan Peran Serta Masyarakat (PSM) rendah dan survailans malaria yang tidak berjalan efektif. $^{12}$

Lingkungan tempat perindukan nyamuk yang berada di sekitar rumah penduduk dengan jarak rumah dengan tempat perindukan nyamuk yang bervariasi secara langsung akan mempengaruhi vektor (nyamuk anopheles) dan parasit (plasmodi$u m$ ). SKD-KLB malaria merupakan kegiatan mendasar bagi pencegahan dan penanggulangan KLB malaria, yang dilakukan dengan melaksanakan pemantauan terhadap kejadian malaria, perubahan lingkungan fisik, timbulnya genangan air, penebangan hutan dan sosial ekonomi. ${ }^{19}$ Mencegah terjadinya infeksi malaria di masyarakat, yang perlu dikakukan ialah upaya pendidikan kesehatan masyarakat (Health Education) dalam bentuk penyuluhan kesehatan masyarakat yang bertujuan agar perilaku individu, kelompok atau masyarakat mempunyai pengaruh positif terhadap pemeli- haraan dan peningkatan kesehatan terhadap malaria.

Kriteria Departemen Kesehatan dan UNICEF, masyarakat di ketiga daerah penelitian tersebut memiliki potensi desa yang cukup baik dan telah memenuhi syarat untuk meningkatkan kegiatan pemberdayaan masyarakat dalam rangka pencegahaan dan pemberantasan malaria, karena telah memiliki: (1) Community Material: ketiga daerah penelitian tersebut terdapat sarana yang cukup memadai untuk dapat meningkatkan kegiatan pencegahan malaria, (2) Community Knowledge: ketiga daerah penelitian tersebut pengetahuan masyarakat mengenai malaria cukup memadai untuk meningkatkan kegiatan pencegahan malaria. ${ }^{17}$

Pemberantasan malaria akan dapat tercapai secara optimal apabila intervensi program malaria diprioritaskan kepada proses dominan yang menyebabkan terjadinya malaria terutama intervensi faktor kontekstual pada tingkat rumah tangga (level 2) dan tingkat desa (level 3) yaitu lingkungan tempat perindukan nyamuk yang berada di sekitar rumah tangga dan jarak rumah dengan tempat perindukan nyamuk, SKD-KLB malaria, penyuluhan kesehatan tentang malaria, kepadatan penduduk dan pertumbuhan penduduk. Faktor ekologi (kontekstual) lainnya seperti kondisi perumahan yang berada dalam parameter habitat, penyemprotan insektisida dan larvasida yang berada dalam parameter kapasitas puskesmas dalam pencegahan primer malaria, endemisitas dan tingkat kemiskinan daerah dalam parameter kondisi sosial ekonomi dan politik daerah yang tersingkir dari model dapat menjadi pertimbangan penting dalam melakukan intervensi pada tingkat rumah tangga (level 2) dan tingkat desa (level 3).

Intervensi pada faktor ekologi (kontekstual) di tingkat rumah tangga dengan melaksanakan manajemen lingkungan (modifikasi lingkungan) tempat perindukan nyamuk seperti rawa-rawa, tambak yang tidak terawat dan lagun akan meniadakan tempat perindukan nyamuk, sehingga akan menghambat perkembangan vektor yang dalam jangka panjang akan menyebabkan daerah tersebut terbebas malaria. Intervensi terhadap lingkungan tempat perindukan nyamuk tersebut dalam jangka panjang akan lebih cost effective dibandingkan dengan intervensi yang dilakukan pada tingkat in- 
dividu dengan melaksanakan kegiatan pencegahan malaria yang berkaitan dengan pengetahuan dan perilaku individu dalam menghindari/mengurangi kontak dengan nyamuk anopheles, seperti pemakaian kelambu, pemakaian obat nyamuk, pemakaian reppelent, dan lain-lain.

Menurut Rijadi bahwa dalam era otonomi daerah, pemerintah daerah kabupaten perlu mempertajam prioritas sasaran program kesehatan yang dapat dikelompokkan menjadi dua kelompok yaitu program yang bersifat public goods yang mempunyai eksternalitas tinggi dan program yang bersifat private goods. ${ }^{20}$ Penelitian yang dilakukan oleh Gani menjelaskan bahwa dampak jangka pendek yang ditimbulkan oleh masalah malaria terhadap sumber daya manusia adalah hilangnya waktu produktif karena sakit dan karena mati, sedangkan dalam jangka panjang masalah malaria akan berdampak terhadap pertumbuhan dan perkembangan otak janin, dampak negatif terhadap efektivitas pendidikan dan dampak negatif terhadap mutu sumber daya manusia. Penelitian tersebut juga menghitung kerugian ekonomi yang disebabkan oleh kejadian infeksi malaria di Kabupaten Lampung Selatan \& Pesawaran Tahun 2003 adalah Rp 4.467.013.889.- Jumlah tersebut adalah 46,9\% dari PAD (Pendapatan Asli Daerah) tahun 2002 sebesar Rp 9.518.594.688.- dan 1,2\% dari APBD (Anggaran Pendapatan dan Belanja Daerah) tahun 2003 sebesar Rp 388.055.975.000.-. ${ }^{21}$

Gambaran tersebut dapat dianalisis secara sederhana, bahwa apabila program pengendalian malaria tetap diprioritaskan kepada intervensi di tingkat individu, maka kerugian secara ekonomi yang diakibatkan oleh kejadian infeksi malaria akan terus berulang sepanjang tahun dengan jumlah kerugian ekonomi yang semakin lama cenderung akan semakin besar yang dimanefestasikan dengan timbulnya dampak kerugian jangka pendek dan jangka panjang terhadap sumber daya manusia akibat kejadian infeksi malaria. Hal ini disebabkan karena tempat perindukan potensial nyamuk di daerah tersebut tetap masih ada, sehingga nyamuk anopheles masih terus dapat berkembang biak sebagai sumber penularan malaria di daerah tersebut yang menyebabkan potensi kejadian infeksi malaria di daerah tersebut tetap tinggi sepanjang tahun. Sebaliknya, bila program pengendalian malaria diprioritaskan kepada intervensi lingku- ngan tempat perindukan nyamuk dengan melakukan modifikasi lingkungan secara optimal yang didukung dengan intervensi pengendalian vektor, maka pembiayaan program pengendalian malaria tampak sangat besar pada tahap awal pelaksanaannya tapi dalam jangka panjang kerugian ekonomi dan dampak jangka pendek dan jangka panjang dari masalah malaria terhadap sumber daya manusia akan menurun bahkan dapat dihentikan. Hal ini disebabkan karena tempat perindukan potensial nyamuk di daerah tersebut sudah diminimalisir atau bahkan tidak ada lagi, sehingga nyamuk anopheles tidak dapat berkembang biak sebagai sumber penularan malaria di daerah tersebut yang menyebabkan menurunnya bahkan hilangnya potensi kejadian infeksi malaria di daerah tersebut.

Semakin memperkuat keyakinan bahwa intervensi program malaria pada lingkungan tempat perindukan nyamuk dengan melaksanakan modifikasi lingkungan yang didukung dengan pengendalian vektor dalam jangka panjang akan lebih cost effective dibandingkan dengan intervensi yang dilakukan pada tingkat individu dengan melaksanakan kegiatan pencegahan malaria yang berkaitan dengan pengetahuan dan perilaku individu dalam menghindari/mengurangi kontak dengan nyamuk anopheles (pemakaian kelambu, pemakaian obat nyamuk, pemakaian repellent).

\section{KESIMPULAN DAN SARAN}

Kejadian infeksi malaria dengan indikator parasit (+) di 30 desa kecamatan endemis malaria (Kecamatan Rajabasa, Padang Cermin dan Punduh Pidada) Kabupaten Lampung Selatan dan Pesawaran adalah 11,2\%. Gambaran jenis plasmodium di 30 desa kecamatan endemis malaria sebagian besar adalah $55,8 \%$ P. Vivax, dikuti dengan P. Falciparum $(41,5 \%)$ dan yang terendah adalah P. Malariae (2,7\%). Peran tingkat individu (level 1) dalam menjelaskan variasi kejadian infeksi malaria $(0,17 \%)$, lebih kecil dibandingkan peran tingkat rumah tangga (level 2) $(43,8 \%)$ ataupun peran tingkat desa (level 3) $(55,9 \%)$.

Pemerintah dan DPRD Kabupaten Lampung Selatan dan Pesawaran dapat membuat langkah-langkah strategis pengendalian malaria melalui: (1) Masalah malaria merupakan prioritas di Kabupaten Lampung Selatan dan Pesawaran, sehingga pengendalian malaria masuk ke dalam 
Kebijakan Umum Anggaran (KUA) Pemerintah Daerah Kabupaten Lampung Selatan dan Pesawaran, membuat peraturan terpadu tentang perizinan, pengawasan dan penertiban pengelolaan tambak dan penggunaan lahan di tiga kecamatan daerah endemis malaria (Kecamatan Padang Cermin, Punduh Pidada dan Rajabasa); (2) meningkatkan dan mengembangkan potensi desa, sumber daya masyarakat dan kegiatan pencegahan malaria masyarakat melalui upaya pemberdayaan keluarga dan masyarakat di daerah endemis malaria (Kecamatan Padang Cermin, Punduh Pidada dan Rajabasa). Dinas Kesehatan Kabupaten Lampung Selatan \& Pesawaran perlu melaksanakan Malariometric Survey dasar yang kemudian diikuti dengan Malariometric Survey lanjutan; (3) pembentukan tim advokasi malaria internal di Dinas Kesehatan Kabupaten Lampung Selatan \& Pesawaran, sehingga program pengendalian malaria masuk ke dalam Rencana Kegiatan dan Anggaran Satuan Kerja Perangkat Daerah (RKA SKPD); (4) peningkatan kualitas kegiatan monitoring dan evaluasi pelaksanaan program pengendalaian malaria di puskesmas serta peningkatan kapasitas puskesmas dalam meningkatkan cakupan diagnostik malaria dengan melakukan kunjungan rumah secara rutin dan terjadwal untuk menemukan penderita malaria (Active Case Detection) dan pengobatan yang tepat pada penderita malaria di wilayahnya dengan memberikan pengobatan radikal menggunakan obat anti malaria yang efeknya kuat terhadap gametosit (gametosida) yaitu, primakuin untuk gametosit P. Falciparum, klorokuin untuk gametosit $P$. Vivax, P. Ovale \& P. Malariae dan kombinasi artemisinin dan amodiakuin (ACT/Artemisinin Combination Therapy) untuk keempat spesies plasmodium yang telah resistensi dengan klorokuin dan primaquin; (5) penentuan prioritas kegiatan program pengendalian malaria yang lebih tepat dalam mencegah, menanggulangi dan memberantas kejadian malaria dengan memprioritaskan program malaria pada determinan di tingkat ekologi (faktor kontekstual) yang berada pada tingkat desa SKDKLB malaria, (6) penyuluhan kesehatan tentang malaria, pertumbuhan penduduk dan kepadatan penduduk dan tingkat rumah tangga (lingkungan tempat perindukan nyamuk di sekitar rumah tangga dan jarak tempat perindukan nyamuk dengan rumah tangga), peningkatan kapasitas puskesmas dalam membangun kemitraan dengan stakeholders terkait dalam melakukan perbaikan manajemen lingkungan (modifikasi lingkungan) di daerah pantai dan tambak terlantar yang potensial menjadi tempat perindukan nyamuk seperti penimbunan, pengeringan dan perataan permukaan tanah serta meningkatkan peran serta masyarakat dalam kegiatan pencegahan dan pemberantasan malaria.

\section{DAFTAR PUSTAKA}

1. Depkes RI. Pedoman Tatalaksana Kasus Malaria di Indonesia. Jakarta: Departeman Kesehatan; 2005.

2. Mursito B. Ramuan Tradisional untuk Penyakit Malaria. Jakarta: Penebar Swadaya; 2002.

3. Sutisna P. Malaria Secara Ringkas. Jakarta: ECG; 2004.

4. Tempo. Ganasnya Demam Kura-Kura: Malaria yang Menyerang Lagi Warga Riau Menyebabkan Belasan Orang Meninggal. Pemakaian Obat yang Berlebihan Justru Berbahaya; 2005. Available at: https://majalah. tempo.co/read/97347/ganasnya-demam-kura-kura

5. Dinkes Provinsi Nusa Tenggara Barat. Profil Kesehatan Provinsi Nusa Tenggara Barat. Mataram: Dinas Kesehatan Provinsi Nusa Tenggara Barat; 2016.

6. Morgensern H. Ecologic Studies. [2nd ed]. In: Rothman K: Lippincott-Reven; 1998.

7. Merlo J, Yang M, Chaix B, Lynch J, Rastam L. A Brief Conceptual Tutorial of Multilevel Analysis in Social Epidemiology: Lingking the Statistical Concept of Clustering to the Idea of Contextual Phenomenon. Journal of Epidemiology \& Community Health. 2005;59(6):443-449.

8. Depkes RI. Kegiatan Litbangkes/Namru-2 di Propinsi Lampung 1999-2002. Jakarta: Badan Penelitian dan Pengembangan Kesehatan (Balitbangkes) Departemen Kesehatan RI; 2003.

9. Dinkes Propinsi Lampung. Analisa Situasi Program Malaria Propinsi Lampung Tahun 2004. Lampung: Dinas Kesehatan Propinsi Lampung; 2004.

10. Sutanto I. Laporan Uji Efikasi Obat Anti Malaria di Propinsi Lampung; 2002.

11. Harijanto P. Malaria Epidemiologi, Patogene- 
sis, Manefestasi Klinis, dan Penanganan. Jakarta: Buku Kedokteran EGC; 2000.

12. Ernawati K, Soesilo B, Duarsa A \& Adah R. Hubungan Faktor Risiko Invidu dan Lingkungan Rumah dengan Malaria di Punduh Pedada Kabupaten Pesawaran Provinsi Lampung Indonesia 2010. MAKARA Kesehatan. 2011;15(2):51-57.

13. Elsey H. The Contextual Determinants of Malaria: Casman EA, Dowlatabadi $H$ (eds). Washington, DC: Resources for the Future, 2002. International Journal of Epidemiology. 2003;32(3):473-474.

14. Hasan A. Faktor-Faktor yang Berhubungan dengan Kejadian Malaria dalam Rumah tangga Desa Hanura Kecamatan Padang Cermin Kabupaten Lampung Selatan \& Pesawaran Tahun 2000. [Skripsi]. Depok: Fakultas Kesehatan Masyarakat Universitas Indonesia; 2001.

15. Sumantri A. Analisis Distribusi Vektor dan
Kasus Malaria di Kabupaten Banjar Negara Jawa Tengah. Jakarta: PT Istaka Advance Management; 2000.

16. Glanz K, Rimer Barbara K \& Viswanath. Health Behavior and Health Education: Theory, Research and Practice. San Francisco: Jossey-Bass; 2008.

17. Depkes RI. Panduan Umum Pemberdayaan Masyarakat. Jakarta: Departemen Kesehatan RI; 1999.

18. Hung, Q Le, Vries, de Peter J., Giao, et al. Control of Malaria: a Successful Experience from Viet Nam. Bulletin of the World Health Organization. 2002;80(8):660-666.

19. Depkes RI. Modul Epidemiologi Malaria. Jakarta: Departemen Kesehatan RI: Dirjen PPM \& PLP; 1999.

20. Rijadi S. Upaya Kesehatan. 2001.

21. Gani A. Dampak Penyakit Malaria Terhadap Sumber Daya Manusia di Kabupaten Lampung Selatan \& Pesawaran. 2004. 